\title{
Integrating a Primary Oral Health Care Approach in the Dental Curriculum: A Tanzanian Experience
}

\author{
Elifuraha G. Mumghamba \\ School of Dentistry, Muhimbili University of Health and Allied Sciences (MUHAS), Dar es Salaam, Tanzania
}

\begin{abstract}
Key Words
Primary oral health care · Dental workforce - Dental curriculum - Oral health care systems - Muhimbili dental curriculum
\end{abstract}

\begin{abstract}
This paper is based on a conference presentation made during the inauguration of the Faculty of Dentistry, Kuwait University, as a World Health Organization Collaborating Centre for Primary Oral Health Care (POHC) on November 27-28, 2012. The aim of this paper is to review how the POHC approach has been integrated into the dental curriculum, sharing the Tanzanian experience as a case presentation from a developing country. The burden of oral diseases worldwide is high, and the current oral health workforce is inadequate to meet the challenges. Curative oral health care is very costly and not accessible to the poor and minorities. To tackle the problem, the $\mathrm{POHC}$ approach rooted in primary health care that emphasizes equity, community involvement, prevention, appropriate technology and a multi-sectorial approach was developed and has been operating for more than 3 decades now. Execution of a comprehensive $\mathrm{POHC}$ requires a trained oral health workforce mix with essential competencies. For this case study, a literature search was done using the search engines subscribed to by the library of Muhimbili University of Health and Allied Sciences, including PubMed, Cochrane, ScienceDirect and Scopus, Wiley-Black-
\end{abstract}

well Interscience, Sage and the Health InterNetwork Access to Research Initiative (HINARI) that gives access to Scirus and Google Scholar. Challenges are discussed with an emphasis more on addressing the common risk factors and determinants of oral health. Integration of the $\mathrm{POHC}$ approach in the dental curriculum for training a competent workforce is crucial in attaining better oral health. Resources are still a major challenge, and the impact of the $\mathrm{POHC}$ approach in the curriculum is yet to be evaluated.

(c) 2013 S. Karger AG, Basel

\section{Introduction}

This paper is based on the conference of the World Health Organization (WHO) Collaborating Centre for Primary Oral Health Care (POHC) and the International Association for Dental Research African and MiddleEast Region in Kuwait, November 27-28, 2012, whereby the Faculty of Dentistry, Kuwait University was inaugurated as the WHO Collaborating Centre for POHC. The $\mathrm{POHC}$ approach is a method that integrates oral health care $(\mathrm{OHC})$ in primary health care (PHC), which was endorsed in 1978 in the Alma-Ata Declaration and emphasizes equity, community involvement, prevention, appropriate technology and a multi-sectorial approach as a key means to attain the goal of 'health for all by the year 2000' [1]. After the 30th anniversary in 2008, the

\begin{tabular}{ll}
\hline KARGER & $\begin{array}{l}\text { () 2013 S. Karger AG, Basel } \\
1011-7571 / 13 / 0237-0069 \$ 38.00 / 0 \quad \text { Karger }\end{array}$ \\
$\begin{array}{l}\text { E-Mail karger@karger.com } \\
\text { www.karger.com/mpp }\end{array}$ & $\begin{array}{l}\text { This is an Open Access article licensed under the terms of the } \\
\text { Creative Commons Attribution-NonCommercial 3.0 Un- } \\
\text { ported license (CC BY-NC) (www.karger.com/OA-license), } \\
\text { applicable to the online version of the article only. Distribu- } \\
\text { tion permitted for non-commercial purposes only. }\end{array}$
\end{tabular}

Elifuraha G. Mumghamba

Muhimbili University of Health and Allied Sciences

PO Box 65014

Dar es Salaam (Tanzania)

E-Mail emumghamba@gmail.com 
emphasis has been on 'primary health care (now more than ever)' a commitment to four fundamental reforms addressing universal coverage, people-centred service delivery, leadership of good governance and healthy public policy [2].

Initially, the essential activities of the $\mathrm{POHC}$ approach were inclined towards oral health promotion, education, prevention and emergency care [3]. Further improvement integrating oral health into general health promotion and chronic disease prevention led to the incorporation of prevention of oral diseases and oral health promotion, as the risks to health are linked [4]. However, at present, the major challenge is to translate knowledge and experience in oral disease prevention and health promotion into active programmes [5]. Specific areas that have gained support from the WHO as priority areas include effective use of fluoride, healthy diet and nutrition, tobacco control, oral health of children and youth through promotion at schools, oral health improvement for the general population and the elderly, general health and quality of life, oral health systems, HIV/AIDS and oral health, oral health information systems, evidence for oral health policy formulation of goals, and research for oral health [4].

The burden of oral health problems is a major public health problem throughout the world (i.e. in both the developing and developed world) as it is of high prevalence and incidence [6] and the burden of treatment, especially in developing countries, is out of reach due to limited resources [7]. Oral diseases have been recognized by the United Nations as an important component of non-communicable diseases [8]. External forces to an individual or group are not sufficient to bring changes towards attaining good oral health, yet oral health promotion is necessary to enable people to increase control over their health and its determinants, and thereby improve their health [9]. Presently, the restrictive understanding of the 'common risk factor approach' should be expanded to encompass action on the common social determinants of oral health [10].

Human resource development has been recognized as a key factor in achieving health for all [11]. Each WHO member state was required to analyse its needs for different types of workers to implement its policies of health for all, adopt suitable health manpower policies, and decide on the numbers and educational qualifications required for each category of personnel. To foster such a workforce, different curricula for each category need to be developed with the necessary competencies stipulated. A dental curriculum may be defined as a planned educa- tional experience for training oral health professionals to manage oral health problems [12]. The main steps for curricular development as recommended by Kern et al. [12] begin with problem identification and a general needs assessment followed by a needs assessment of targeted learners, formulation of goals and objectives, educational strategies, implementation and, finally, evaluation and feedback. Information from worksites through 'tracer studies' is very useful in the exercise of curriculum development, particularly at the step of needs assessment, as it will provide information on how well graduates thought they had been prepared for their work responsibilities, whether their supervisors felt that the graduates were able to perform as expected, and the graduates' opinions about their learning environment $[13,14]$. The aim of this paper is to review how the POHC approach has been integrated into the dental curriculum, sharing the Tanzanian experience from the Doctor of Dental Surgery (DDS) curriculum of the Muhimbili University of Health and Allied Sciences (MUHAS) as a case presentation from a developing country - East Africa.

\section{Materials and Methods}

A computer search of the literature was done through the search engines subscribed to by the university library, including PubMed, Cochrane, ScienceDirect and Scopus, Wiley-Blackwell Interscience, Sage and the Health InterNetwork Access to Research Initiative (HINARI) that gives access to Scirus, Google Scholar [15] and other organizational repositories. The key words used were, 'primary oral health care' ( $\times 89$ articles), 'primary oral health care approach' $(\times 355)$, 'dental curriculum' $(\times 433)$, 'POHC approach and dental curriculum' $(\times 47)$ and other related terms, particularly 'workforce' $(\times 19)$, 'manpower' $(\times 45)$, 'human resource' $(\times 150$, access $\times 19)$, and 'inequalities/disparities in oral health care' $(\times 33)$. To filter the documents, the publications considered were confined to those in English published between 1978 and 2013. The search results gave title summaries that were scrutinized by the author to select relevant abstracts which were reviewed for important articles to be downloaded. Relevant titles that had no abstracts but had full journal articles or institutional repositories accessible were downloaded directly for review. Relevant titles lacking an abstract, not directly accessible online, and without a hard copy in the university (MUHAS) medical library were excluded in this presentation. The inclusion criteria encompassed all articles pertaining to the dental curriculum (types and models of learning) and $\mathrm{POHC}$ approach and related components, especially accessibility, community involvement and workforce. The exclusion criteria included all articles on solitary presentation with no integration of the components considered above. The dental curriculum from the author's institution (MUHAS) for training dentists [16] was included as a 'case presentation' to share the Tanzanian experience on how it has integrated the POHC approach into the curriculum.
Mumghamba 


\section{Results}

Accessibility to curricula of different dental institutions with full details on the integration of the POHC approach into their curricula for different oral health workforce mix is limited.

\section{Dental Curricula from Different Institutions}

Dental curricula include an oral health curriculum for Bachelor of Dental Sciences at the University of Western Australia to address the oral health of indigenous Aboriginals and Torres Strait Islander people with special attention to social and cultural matters [17]. Other curricula dealt with were oral health (dental) modules being taught in other health discipline courses. In South Africa, for example, the Primary Health Care Nursing Course was launched to sensitize nurses on oral health matters by increasing their knowledge and skills [18] and reach underserved populations, i.e. the aging and those with disabilities in the USA [19]. In the USA, a training programme named 'Smiles for Life, a National Oral Health Curriculum' under the Inter-Professional Alliance on Oral Health, has been approved by the American Dental Association [20]. The University of Oklahoma is one university that has been involved in training new members of the dental team, community dental health coordinators (CDHC), to work under the dentist in line with the American Dental Association recommendations [21].

\section{MUHAS DDS Curriculum - A Case Presentation}

The school (School of Dentistry) started in 1979 with the traditional teacher-centred lecture/practical/clinicalbased DDS curriculum that was transformed to a competence-based curriculum (CBC) in 2011 [16]. The CBC is a 10-semester programme that includes basic science courses (semesters 1-4) and clinical dentistry courses which incorporates general medicine and surgery as well as preventive and community dentistry from semesters 5-10. Within the semester, the courses are modularized for the basic science courses, whereas for the clinical courses they are organized as modules or a 'rotation' with junior and senior rotation. The current $\mathrm{CBC}$ has benefited from the recent university-wide (MUHAS) tracer study [14] whereby areas that needed improvement were revised to keep up to the standards. New courses had to be introduced to impart the required competencies in specific fields, especially in information technology, ethics, communication and professionalism across all undergraduate programmes including the DDS programme [22].

Primary Oral Health Care Approach and Dental Curriculum
Using Bloom's taxonomy, a system of classification of educational learning objectives [23], the objectives in different modules in the curriculum addressed the cognitive (knowledge) domain, psychomotor (skill) domain, and affective domain (attitudes). The objectives were carefully written to reflect Bloom's taxonomy's gradual process of developing the main domain from a simple to a more advanced stage of complex concepts. For example the 'cognitive domain' had six levels, beginning with knowledge and followed by comprehension, application, analysis, synthesis and evaluation. The 'psychomotor domain' had five levels starting with initiation as the first step before manipulation, precision, articulation and naturalization. Finally, the 'affective domain' had five levels, hierarchically composed of receiving, responding, valuing, organization and characterization.

This DDS CBC is rooted in eight main 'MUHAS competencies' with specific details for each competence as a guide (table 1). The competencies include professional knowledge, practical/clinical skills, relationship with patients, clients and communities, relationship with colleagues, teaching skills, maintaining good practice, working within the health care system, and maintaining professionalism. Most medical institutions worldwide have six competencies [24] and the additional two competencies unique for MUHAS were the 'relationship with colleagues' and 'teaching skills' [16, 22].

The integration of the POHC approach in this dental $\mathrm{CBC}$ is particularly conducted in semesters 6,8 and 10 under the courses of preventive and community dentistry, where they also learn oral health promotion. The competence-based specific objectives for this module are adequately described following the cognitive, psychomotor and affective domains in Bloom's taxonomy (table 2). The educational strategies or teaching methods include lectures, seminars, practicals/clinicals, and community oral health participation field rotations. The theoretical teaching introduces the students to PHC and its five pillars: equity, community involvement, focus on prevention, appropriate technology and a multi-sectorial approach [1] and concepts of health promotion $[9,25]$. The seminars deal with student presentations and discussions on the same level to instil empathy, and on the practicability, feasibility and challenges of teaching based on the local environment.

The community participation field rotations, famously known as the 'Morogoro rotation', presents an interesting environment conducive to learning conducted about $200 \mathrm{~km}$ from the main university campus 
Table 1. MUHAS competencies specific for training dentists (DDS)

Professional Apply knowledge of the structure and functions of human body in management of oral-facial diseases; demonstrate knowledge knowledge of the causes and mechanisms of diseases; employ knowledge of physical, psychological and sociocultural factors in the causation and progression of diseases; develop clinical reasoning to solve oral-facial problems; employ knowledge of pathophysiology of communicable diseases; use knowledge of pathophysiology of noncommunicable diseases; apply knowledge of common oral surgical conditions and emergencies; examine common oral-facial conditions during childhood in Tanzania to appropriately manage childhood oral-facial diseases

Practical/ Gather complete and focused histories in an organized manner; conduct complete oral-facial and relevant physical clinical skills examination in a systematic manner; document the findings in an organized and comprehensive manner; formulate and prioritize correct and appropriate patient management plans; use and maintain dental instruments and equipment; perform common oral-facial procedures and alleviate patients' pain; follow universal precautions and sterile technique; anticipate patients' needs; provide appropriate patient care; participate in discharge planning and create individualized disease management and/or prevention plans including patient self-management and behaviour change; demonstrate confidence and comfort with the primary provider role and the provision of longitudinal care

Relationships Establish constructive relationships and communicate effectively with patients, clients and/or communities; provide with patients, service to individuals and groups that is appropriate to their different backgrounds; communicate health issues and clients and polices effectively to the public

communities

Relationships Listen to and take advice from colleagues; motivate colleagues; contribute effectively to team work; work effectively with colleagues with other health professionals

Teaching skills Prepare and deliver effective health promotion messages to educate communities; teach a course for health professionals or students

Maintaining Systematically evaluate one's own performance and practice; regularly seek information necessary to improve good practice professional practice (life-long learning); apply evidence-based decision making; participate in applied research activities; use information technology to optimize learning; show leadership and managerial skills

Working within Show knowledge of how the health care system functions (structures, policies, regulations, standards and guidethe system and lines); work effectively in various health care delivery settings and systems (hospitals, government, ministries, context of NGO's, communities, industry); coordinate and implement health service delivery and health interventions within health care the health care system; incorporate considerations of cost effectiveness into health service delivery; incorporate considerations of patient cost burden into health service delivery; promote quality care in health systems through audits, accreditations, and/or evaluations; identify system challenges and implement potential solutions

Professionalism Maintain ethical standards (confidentiality, informed consent, avoid practice errors, avoid conflicts of interest); apply entrepreneurial skills for advancement of practice and the profession; show sensitivity and responsiveness to diversity (culture, age, socioeconomic status, gender, religion, and disability)

Source: MUHAS DDS curriculum, October 2011.

against the backdrop of the spectacular Uluguru Mountains and lowlands teeming with the prestigious wildlife that attracts tourism, the Mikumi National Park. During this rotation, students are given the opportunity to work in rural primary and secondary schools and reproductive and child health clinics within the health care system. Activities to be accomplished during the rotation include creating cooperative working relationships with the relevant community, arranging oral health examination exercises in the field for data collection for class use, organizing oral health education sessions, promoting oral health, rendering oral emergency care, and providing atraumatic restorative treatment care. Also, in col- laboration with the local staff at that health care facility, the students give nutrition counselling and take part in the assessment of mothers and children in terms of assessing blood pressure and measuring the weight and height of mothers and children. Towards the end of the rotation, each student is given an opportunity to work with the regional dental officer for 2 weeks in any regional dental clinic in the country. The aim is to allow the students to gain some leadership skills needed to oversee POHC activities in the region, where after graduation they will work as team leaders. During training and at the end of the preventive and community course, the student will be assessed on course objectives that are 
Table 2. Objectives of POHC and oral health promotion module

\begin{tabular}{ll}
\hline Aim & $\begin{array}{l}\text { This module is intended to provide a student } \\
\text { with essentials of primary OHC and oral health } \\
\text { promotion }\end{array}$ \\
\hline $\begin{array}{l}\text { Competence- } \\
\text { based } \\
\text { objectives }\end{array} \quad \begin{array}{l}\text { At the end of this module, a student will be able } \\
\text { to: }\end{array}$ \\
Demonstrate knowledge of how the health \\
& care system functions (structures, policies, \\
- & Plan and carry out an oral health intervention \\
& using the principles of PHC and health \\
& promotion \\
- & Demonstrate respect to clients and \\
& communities with different backgrounds in \\
& the process of undertaking community \\
& dentistry \\
- & Demonstrate the ability to work effectively \\
& with other health professionals and contribute \\
& effectively to teamwork \\
- & Maintain professional and ethical standards \\
& especially by showing sensitivity and \\
& responsiveness to diversity (culture, age, \\
& socioeconomic status, gender, religion, and \\
& disability) in discharging duties of a \\
& community dentist \\
- & Demonstrate leadership and managerial skills \\
& in discharging duties of a community dentist \\
- & Deliver effectively well-prepared health \\
& promotion messages to individuals and \\
& communities
\end{tabular}

Source: MUHAS DDS curriculum, October 2011.

aligned to the eight MUHAS competencies by formative assessment tests and summative examination using different strategies.

\section{OHC Systems}

The POHC approach operates within the existing health care system in each country. The POHC workforce is employed by the health care system and discharges duties according to a specific job description. Every member of the POHC workforce is required to attain competence in working with the health care system and for this reason it is one of the six common competencies recognized worldwide [24] and one of the eight MUHAS competencies (table 1). The WHO addresses health systems as a result of combined efforts of government agencies, institutions and resources with the main aim of improving the health of the people [26], and it implies the inclusion of oral health. The OHC system incorporates all efforts directed to improve oral health. In developed countries, most of the OHC systems involve the private sector, while in developing countries the system is managed by the public sector with some assistance from non-governmental organizations and faith-based organizations. To elaborate this point, the President of the United Republic of Tanzania, for example, has been a leading promoter of oral health in the country, as reported by the Miracle Corners of the World, a non-governmental organization based in New York, USA $[27,28]$ and which is now worldwide, as narrated by the Press News Wire [29]. The President, His Excellency Dr. Jakaya Mrisho Kikwete, urged the United Nations Summit on Non-Communicable Diseases in New York (September 22, 2011) to address the challenge of oral health as a priority on the agenda. $\mathrm{He}$ implored fellow heads of state and governments to include oral health among the non-communicable diseases and for health ministries to become more engaged [28].

The performance of $\mathrm{OHC}$ systems worldwide varies depending upon the economic capability and human resources available [30]. An extreme example may be that in developed countries with established economies patients are managed with oral implants, whereas in developing countries with emerging economies the governments are still at the level of striving to provide access for its people to implement prevention-based solutions on a common risk factor approach [31] and to provide safe emergency $\mathrm{OHC}$ that constitutes tooth extractions and possibly limited restorative care by atraumatic restorative treatment [32], and to a lesser extent low-cost periodontal therapy [33]. It is in these countries that the basic package for oral care has been advocated [34].

The concept of atraumatic restorative treatment and basic package for oral care needs to be incorporated in all current curricula for training the oral health workforce [35] as well as in a continuing education and professional development programme.

\section{Workforce Mix for $\mathrm{OHC}$}

To be able to adequately deliver OHC effectively to those in need it is necessary to have the proper mix of oral health workforce. Each workforce category requires a different curriculum for training. The most recommended oral health workforce mix includes general dentists, specialist dentists, dental therapists, dental hygienists, dental assistants, dental technologists and, more recently, the CDHC. The specific job description for each category and their limitations are usually given by the relevant authorities but in general it includes the following:

Dentist. The general dental practitioner or general dentist is a team leader of all other cadres at the work 
place [36], whose task is to comprehensively manage all patients with oral health problems in a private dental office, private or public hospital, and even in other governmental institutions such as the armed forces and non-governmental organizations. The training period is 4-6 years.

Dental Hygienists. Dental Hygienists, as part of the OHC team, work in collaboration with the dentist or independently with a limited scope of practice, for example treating more school children and fewer adults, depending on the training curriculum and law governing the practice, but their main task is to insure the prevention of oral diseases and emphasize oral health promotion $[3,37$, 38].

Dental Therapist. The dental therapist historically has developed from dental nurses in New Zealand $[3,37]$ for the purpose of improving access to $\mathrm{OHC}$, and now dental therapists are recognized in more than 53 countries in the world [3]. The scope of practice in developing countries has been limited to basic preventive, restorative and minor surgical procedures.

Community Dental Health Coordinator. The CDHC is a new category in the workforce - an alternative that is currently being piloted in the USA to address the longstanding problem of access to $\mathrm{OHC}$ [39]. The CDHC will work under the dentist and will be responsible for the following: giving oral health education, prevention, oral health promotion, organizing clinical outreach visits, and limited preparatory clinical treatment procedures to be completed by the dentist. The $\mathrm{CDHC}$ training is a 3 -year programme and thereafter the graduates are expected to go back and work in their home communities [40].

Dental Assistants. Dental assistants form the other cadre of the OHC team usually engaged as supportive and assisting staff to the dentist. The responsibilities of dental assistants include managing the dental office, receiving and preparing patients to be managed by the dentist, controlling cross-infection in the dental clinic or office, preparing instruments for restorative care, charting patient treatment, and giving oral hygiene instructions. They can also process the X-ray films, take impressions of the patients' teeth and make cast study models [41].

Dental Technologist. The dental technologists are part of the dental team responsible for the fabrication and repair of different types of dental appliances under the prescription of the dentist as demanded, planned and agreed upon with the patient [42]. The dental technologists are different from the 'denturists' as the latter are also trained to attain clinical skills for edentulous patients.

\section{Curricula Types and Models of Learning}

The type of the curriculum and model of learning to be used should be relevant to the population to be served. It should not only equip the graduates with the knowledge, skills, attitudes and behaviour but should also accommodate the culture and social principles acceptable to the community they will serve for achieving the best outcome. There are different types of curricula and models of learning with different characteristics, depending on whether it is teacher or student centred, and whether it emphasizes cognitive, affective or psychomotor domains or a combination.

Lecture-Based Curriculum. The lecture-based curriculum has traditionally been in use in dental and medical schools and it puts the lecturer (teacher) at the centre in the teaching process, but recently it has been found to accomplish less in self-reflection, self-efficacy and self-directed learning compared to problem-based learning (PBL) methods [43].

Problem-Based Learning. A PBL curriculum positions the learner (student) at the centre of the learning experience. Early clinical exposure and integration of clinical and classroom experience, prevalent in PBL, have been considered as one explanation for superior skills in social and cognitive performance of PBL graduates [44]. The systematic review of Polyzois et al. [45] indicates that PBL has a number of positive effects in key areas of student education that include perceptions of learning environment, clinical performance, and communication with the patient, but there is limited high-quality evidence to prove its superiority over teacher-centred education.

Competence-Based Curriculum. The CBC is largely centred on a student working in collaboration with the teacher on the acquisition of specific competencies at an acceptable standard that integrates well the necessary knowledge, skills, attitudes and behaviour unique for a particular profession such as, for example, a general dentist or a dental hygienist. In this CBC the emphasis is the attainment of the necessary competence and therefore the time for training is variable to accommodate learners of different paces [46].

\section{Discussion}

A POHC approach is rooted in the five $\mathrm{PHC}$ principles [1] and further improvement in PHC, especially in relation to the current version of 'primary health care (now more than ever)' [2] where all its reforms in four major areas, including good governance, have to be incorpo-
Mumghamba 
rated into the POHC approach. These characteristics need to be translated into qualities of the oral health care workforce in the form of competencies so that their tasks in the form of job descriptions after graduation from dental or training institutions may be effectively discharged. However, the importance of life-long learning qualities [47] of the workforce is necessary because no one can learn during a short training period all that is needed in the field of practice because of the many dynamic processes constantly taking place. For example, new diseases continue to emerge, while the development of new technology and treatment materials requires continuing education and professional development. Since the workforce mix is produced through a specific dental curriculum, revision of these curricula is necessary periodically for the purpose of incorporating the necessary developments. The case study of the MUHAS DDS curricula is such an example, which by its own merits had to be transformed to a CBC [16]. The curriculum review process needs to be done carefully in a well-planned manner to make sure that all important factors are incorporated. Tracer studies are among the methods that have yielded invaluable insight, especially about what is needed in the actual field of practice, i.e. the challenges, and probably the most appropriate way of handling matters through appropriate technology, among many others $[13,14]$. The type of workforce mix necessary to provide an $\mathrm{OHC}$ that is accessible to all people, rich and poor, urban and rural, and that addresses the burden of oral diseases has been a challenge to both developed and developing countries [3, $6,7,37,39$ ]. One area is problematic: services provided as a private business attract qualified dentists to deliberately set up their businesses in urban areas, leaving the rural, the poor and minorities under-served $[48,49]$. Approaches to resolve these challenges may take different courses, but at least it should be seen that the needy population is not left without any proper OHC [1]. Training of dental therapists has been one way that has helped most developing countries [3], while among the developed countries it has only been adopted by a few oral health authorities [50-52]. The WHO supports integration because the traditional model of using dentists for curative care has not been cost-effective [53]. However, many in the USA are resisting its acceptance for fear that the cadre is lacking the necessary clinical skills or competencies [54] and that it is a 'disrupting innovation' $[55,56]$. This has led to a proposal that invites a new category of worker into the oral health team, the $\mathrm{CDHC}$, now being piloted in the USA [39] with much orientation aimed at prevention. The long-term effectiveness of this cadre is yet to be eval-

Primary Oral Health Care Approach and Dental Curriculum uated. Since there is sometimes unwillingness to allow members of the workforce to provide services to some of the communities, for reasons that have been discussed, and because this may be a barrier to improving $\mathrm{OHC}$, the cadre of CDHC is being recruited from the same community that it will serve after graduation [40]. Training students adequately to attain professionalism is the best approach and must include even those with special disabilities $[19,57,58]$. Each category of the oral health workforce must be trained using approved curricula, which varies from one country to another. During implementation of the curricula, care has to be taken that all the designated competencies under the main domains are attained, otherwise discrepancies may be observed in the field of practice [59] where, for example, knowledge (cognitive domain) may not effectively be translated into practice (skill domain).

For the purpose of improving the $\mathrm{POHC}$ approach, it would be appropriate that traditional curricula be reviewed to incorporate the common risk factor approach together with actions on determinants of health, apart from concentrating on behavioural issues alone [10]. Such considerations need to be integrated into the curriculum to get the best results. As has been reported by Yee and Sheiham [7], when treating dental caries in developing countries is out of reach, embarking on preventive measures is the most rational approach to solving OHC problems. The 'Morogoro rotation' in preventive and community dentistry in the MUHAS DDS curriculum presented as a case study is one of the model curricula for the integration of the $\mathrm{POHC}$ approach into the dental curriculum. However, as the curriculum is run in a developing country where most of the dental schools are financially supported by a government that has many burdens from other sectors, adequate budgeting is not always forthcoming and institutions are recommended to 'tighten their belts' and not to expect further support from the government. It is unfortunate that under such constraints some changes may be introduced into the implantation of the curriculum, in particular compressing the time allocated for field work. Although PHC is an 'essential health care based on practical, scientifically sound and socially acceptable methods and technology made universally accessible to individuals and families in the community through their full participation and at a cost that the community and the country can afford to maintain at every stage of their development in the spirit of self-reliance and self-determination' [1], implementation still poses a challenge to dental training institutions, especially at a time of financial crisis. 


\section{Conclusion}

A case study of a CBC has been presented herein. Integration of the POHC approach in the dental curriculum with a full range of desired competencies for a specific job is crucial. Continued improvements need to be made, based on the impact and challenges that arise during the implementation period. Resources are still a challenge. It is recommended that an evaluation be made after the first cohort has graduated and employed to assess its impact. An effective POHC approach depends on a competently trained workforce.

\section{Disclosure Statement}

The author declares that no financial or other conflict of interest exists in relation to the content of the article.

\section{References}

1 World Health Organization, UNICEF: Report of the Conference on Primary Health Care, Alma-Ata, USSR, 6-12 September 1978. Geneva, WHO. http://www.who.int/ publications/almaata_declaration_en.pdf (accessed January 7, 2013).

2 World Health Organization: The World Health Report 2008 - Primary Health Care (Now More Than Ever). http://www.who.int/ whr/2008/en/ (accessed September 4, 2013).

- 3 Nash DA, Friedman JW, Kardos TB, et al Dental therapists - a global perspective. Int Dent J 2008;58:61-70.

4 Petersen PE: The World Oral Health Report 2003: continuous improvement of oral health in the 21st century - the approach of the WHO Global Oral Health Programme. Community Dent Oral Epidemiol 2003;31(suppl 1):3-23.

5 Petersen PE: Global policy for improvement of oral health in the 21 st century - implications to oral health research of World Health Assembly 2007, World Health Organization. Community Dent Oral Epidemiol 2009;37: $1-8$.

-6 Petersen PE, Bourgeois D, Ogawa H, et al: The global burden of oral diseases and risks to oral health. Bull World Health Organ 2005;83: 661-669.

7 Yee R, Sheiham A: The burden of restorative dental treatment for children in Third World countries. Int Dent J 2002;52:1-9.

8 UN Declaration 2011. http://www.un.org/ga/ search/view_doc.asp?symbol=A/66/L.1 (accessed January 8, 2013).

9 Ottawa Charter for Health Promotion: First International Conference on Health Promotion. Ottawa, 21 November 1986. WHO/ HPR/HEP/95.1.

10 Watt RG: Social determinants of oral health inequalities: implications for action. Community Dent Oral Epidemiol 2012;40: 44-48.

11 World Health Organization: Targets for health for all, targets in support of the European regional strategy for health for all. Copenhagen, WHO Regional Office for Europe, 1985, second impression 1986, pp 141-144.
12 Kern DE, Thomas PA, Howard DM, et al: Curriculum Development for Medical Education - A Six Step Approach. Baltimore, Johns Hopkins University Press, 1998.

13 Mkude DJ, Ishumi AG: Tracer Studies in a Quest for Academic Improvement, University of Dar es Salaam. Dar es Salaam University Press, 2004, pp 179-195.

14 Pemba S, Macfarlane SB, Mpembeni R, et al: Tracking university graduates in the workforce: information to improve education and health systems in Tanzania. J Public Health Pol 2012;33:S202-S215.

15 WHO-HINARI. www.who.int/hinari/faq/ general_information/en/index.html (accessed December 28, 2012).

16 Loomer PM, Masalu JR, Mumghamba E, et al: New curriculum in dentistry for Tanzania: competency-based education for patient and population health (2008-2011). J Public Health Pol 2012;33:S92-S109.

17 Bazen J, Paul D, Tennant M: An aboriginal and Torres Strait Islander oral health curriculum framework: development experiences in Western Australia. Aust Dent J 2007;52:8692.

18 Ogunbodede EO, Rudolph MJ, Tsotsi NM, et al: An oral health promotion module for the primary health care nursing course in Acornhoek, South Africa. Public Health Nurs 1999; 16:351-358.

19 Hahn JE, Fitzgerald L, Markham YK, et al: Infusing oral health care into nursing curriculum: addressing preventive health in aging and disability. Nurs Res Pract 2012;2012: 157874.

20 American Dental Association: Groundbreaking oral health curriculum endorsed by American Dental Association. http://www.ada. org/7666.aspx (accessed November 19, 2012).

21 American Dental Association: First group of community dental health coordinators complete ADA pilot program, Oklahoma University, November 4, 2010. http://www.ada. org/5030.aspx (accessed January 28, 2013).

22 Ngassapa OD, Kaaya EE, Fyfe MV, et al: Curricular transformation of health professions education in Tanzania: the process at Muhimbili University of Health and Allied Sciences
(2008-2011). J Public Health Pol 2012; 33:S64-S91.

23 Bloom's taxonomy. http://www.businessballs. com/bloomstaxonomyoflearningdomains. htm (accessed November 4, 2012).

24 Swing SR: The ACGME outcome project: retrospective and prospective. Med Teach 2007; 29:648-654.

25 Bangkok Charter 2005. http://www.who.int/ healthpromotion/conferences/6gchp/hpr 050829_\%20BCHP.pdf (accessed November 4, 2012).

26 WHO: Health Systems. http://www.who.int/ healthsystems/EN_HSSkeycomponents.pdf (accessed December 30, 2012).

27 Miracle Corners of the World. http://www. mcwglobal.org/userfiles/2009\%20MCW\%20 Tanzanian\%20President $\% 20$ Honorary\%20 Dinner.pdf (accessed December 30, 2012).

28 Miracle Corners of the World. http:// mcwglobal.org/Accordion. asp? cid = 12 (accessed December 30, 2012).

29 Kikwete JM: Press News Wire. http://www. prnewswire.com/news-releases/tanzanianpresident-he-jakaya-m-kikwete-calls-forunited-nations-summit-on-noncommunicable-diseases-ncds-to-includeoral-disease-130339138.html (accessed December 30, 2012).

30 Kindelman D, Arpin S, Baez RJ, et al: Oral health care systems in developing and developed countries. Periodontology 2000 2012; 60:98-109.

31 Petersen PE, Jurgensen N: Oral health and care in low-income countries; in Kahabuka FK, Kikwilu EN, Kida IA (eds): Oral Health Care for Socially Disadvantaged Communities. New York, NOVA Science, 2012, pp 19-36.

32 Kikwilu EN: A systematic introduction of the ART approach in government dental clinics in Tanzania; thesis, Radboud University Nijmegen, 2009. http://repository.ubn.ru.nl/ bitstream/2066/74422/1/74422.pdf (accessed December 30, 2012)

33 Slots J: Low-cost periodontal therapy. Periodontology 2000 2012;59:1-29.

34 van Palenstein Helderman W: Priorities in oral health care in non-EME countries. Int Dent J 2002;52:30-34. 
35 Frencken JE, Leal SC, Navarro MF: Twentyfive-year atraumatic restorative treatment (ART) approach: a comprehensive overview. Clin Oral Investig 2012;16:1337-1346.

36 Prospects: General dental practitioner. http:// www.prospects.ac.uk/dentist_job_description. htm (accessed December 30, 2012).

37 Coates DE, Kardos TB, Moffat SM, et al: Dental therapists and dental hygienists educated for the New Zealand environment. J Dent Educ 2009;73:1001-1008.

38 Ohrn K: The role of dental hygienists in oral health prevention. Oral Health Prev Dent 2004;2:277-281.

$>39$ McKinnon M, Luke G, Bresch J, et al: Emerging allied dental workforce models: considerations for academic dental institutions. J Dent Educ 2007;71:1476-1491.

40 American Dental Association: CDHC job description. http://www.ada.org/3500.aspx (accessed November 22, 2012).

41 College of Southern Idaho: Dental assistants. http://hshs.csi.edu/dental_assistant/ (accessed November 22, 2012).

42 British Dental Association: Dental technologists. http://www.bda.org/dcps/work-indent/technician-technologist.aspx (accessed November 22, 2012).

43 Grant A, Kinnersley P, Field M: Learning contexts at two UK medical schools: a comparative study using mixed methods. BMC Res Notes 2012;5:153.
44 Neville AJ: Problem-based learning and medical education forty years on. A review of its effects on knowledge and clinical performance. Med Princ Pract 2009;18:1-9.

45 Polyzois I, Claffey N, Mattheos N: Problembased learning in academic health education. A systematic literature review. Eur J Dent Educ 2010;14:55-64.

46 Saucier D, Shaw E, Kerr J, et al: Competencybased curriculum for family medicine. Can Fam Physician 2012;58:707-708.

47 Osazuwa-Peters N: The Alma-Ata Declaration: an appraisal of Nigeria's primary oral health care three decades later. Health Policy 2011;99:255-260.

48 Felland LE, Lauer JR, Cunningham PJ: Community efforts to expand dental services for low-income people. Issue Brief Cent Stud Health Syst Change 2008;122:1-4.

49 Draper DA, Ginsburg PB: Health care cost and access challenges persist: initial findings from HSC's 2007 site visits. Issue Brief Cent Stud Health Syst Change 2007;114:1-6.

50 Nash DA: Adding dental therapists to the health care team to improve access to oral health care for children. Acad Pediatr 2009a; 9 : 446-451.

51 Robert Wood Johnson Foundation: Dental health aides and therapists in Alaska. http:// www.rwjf.org/pr/product.jsp?id=71655 (accessed November 22, 2012).
52 Minnesota - US Bill 2009. http://www.senate. leg.state.mn.us/members/member_pr_display. php?ls=86\&id=2508 (accessed November 22, 2012).

53 Monajem S: Integration of oral health into primary health care: the role of dental hygienists and the WHO stewardship. Int J Dent Hygiene 2006;4:47-51.

54 Bailit HL, Beazoglou TJ, DeVitto J, et al: Impact of dental therapists on productivity and finances. I. Literature review. J Dent Educ 2012;76:1061-1067.

55 Edelstein BL: Examining whether dental therapists constitute a disruptive innovation in US dentistry. Am J Public Health 2011;101: 1831-1835.

56 Mathu-Muju KR: Chronicling the dental therapist movement in the United States. J Public Health Dent 2011;71:278-288.

57 Cowpe J, Plasschaert A, Harzer W, et al: Profile and competences for the graduating European dentist - update 2009. Eur J Dent Educ 2010;14:193-202.

58 Faulks D, Freedman L, Thompson S, et al: The value of education in special care dentistry as a means of reducing inequalities in oral health. Eur J Dent Educ 2012;16:195201.

59 Hajizamani A, Mohammadi TM, Hajmohhamadi E, et al: Integrating oral health care into primary health care system. ISRN Dent 2012;2012:657068. 